\title{
Isothermal fatigue behaviours of Mg-12Gd-3Y-0.5Zr magnesium alloy at elevated temperatures
}

\author{
Xiao Ming YANG ${ }^{1, a}$ \\ ${ }^{1}$ Jingchu University of Technology, JinMen City, HuBei province, china
}

\begin{abstract}
Isothermal fatigue tests were carred out on Mg-12Gd-3Y- $0.5 \mathrm{Zr}$ magnesium alloy and its heat-treated counterpart at different temperatures. The exprimental results shows that isothermal fatigue strength of two alloys decrease very slowly with increasing temperature up to $200^{\circ} \mathrm{C}$. The ultimate tensile strength of heattreated Mg-12Gd-3Y-0.5Zr is slight lower than that of as-rolled counterpart, however, the fatigue strength of heat-treated alloy is higher.
\end{abstract}

\section{Introduction}

Magnesium alloys are called green-engineering materials with great development potential because of their many outstanding advantages, such as low density, high specific strength and specific stiffness, good machinability and castability, etc.[1]. Numerous magnesium alloy products have been used in automobile, communication and aerospace industries [2]. However, there are some serious shortcomings, one of which is poor mechanical property at high temperature that limits the applications of magnesium alloys in the corresponding conditions. In recent years, many attempts have been made to improve the mechanical properties of magnesium alloys. Equal channel angular pressing (ECAP), as one effective method of severe plastic deformation (SPD), can modify the microstructure and texture of magnesium alloys and improve the tensile properties to some extent [3].

In this paper, the ultimate tensile strength and isothermal fatigue strength at different temperatures are reported. With added rare earth elements, the as-rolled and heat-treated Mg- $12 \mathrm{Gd}-3 \mathrm{Y}-0.5 \mathrm{Zr}$ alloys show the high tensile strength and decent fatigue strength at elevated temperatures. The strengthening and the fatigue failure mechanisms are discussed in this paper.

\section{Experimental}

The ingots of Mg-12Gd-3Y-0.5Zr alloy were rolled with a ratio of $25: 1$ at $400{ }^{\circ} \mathrm{C}$. For comparison, part of the as-rolled alloy was further heat-treated in a furnace at $415^{\circ} \mathrm{C}$ for 16 hours and then cooling in air.
Tensile and isothermal fatigue specimens were cut by electric spark machining along the rolling direction with a gauge sections of $3 \mathrm{~mm} \times 1.4 \mathrm{~mm} \times 1 \mathrm{~mm}^{3}$ and $20 \mathrm{~mm} \times 4 \mathrm{~mm} \times 3 \mathrm{~mm}^{3}$ respectively. Tensile tests were carried out on an Instron 8801 testing machine equipped with a heater and temperature controlling system at room temperature, $130,170,200$ and $235^{\circ} \mathrm{C}$ and at a strain rate of $1 \times 10^{-3} \mathrm{~s}^{-1}$. Isothermal fatigue tests were carried out on an MTS810 testing machine at room temperature, 100, 200 and $235^{\circ} \mathrm{C}$ and at a frequency of $20 \mathrm{~Hz}$ under stress control. The stress wave form was triangular, and the load ratio $\mathrm{R}=0.1$.

The fracture surface morphologies of the specimens were observed by a Cambridge S360 scanning electron microscope (SEM). For TEM observations, slices with a thickness of $0.6 \mathrm{~mm}$ were cut from the section parallel to the rolling direction, mechanically thinned to about $50 \mu \mathrm{m}$ and cut into discs with diameters of $3 \mathrm{~mm}$. Thin foils were made from these discs with a twin-jet polisher with a current of $40 \mu \mathrm{A}$ using an electrolyte of $20 \% \mathrm{HNO}_{3}$ in methanol at $248 \mathrm{~K}$. The thinned foils were observed using a TEM $2000 \mathrm{FX}$ II operating at $200 \mathrm{KV}$.

\section{Experimental results and discussion}

\subsection{Tensile properties at different temperatures}

Temperature dependence of ultimate tensile strengths of the as-rolled and heat-treated $\mathrm{Mg}-12 \mathrm{Gd}-3 \mathrm{Y}-0.5 \mathrm{Zr}$ alloys is shown in Fig. 1 for tests carried out at room temperature, $130,170,200$ and $235^{\circ} \mathrm{C}$. Ultimate tensile strength of the as-rolled $\mathrm{Mg}-12 \mathrm{Gd}-3 \mathrm{Y}-0.5 \mathrm{Zr}$ reaches the highest at $405 \mathrm{MPa}$ at room temperature. Ultimate tensile strength of the heat-treated $\mathrm{Mg}-12 \mathrm{Gd}-3 \mathrm{Y}-0.5 \mathrm{Zr}$ is a bit lower than that of the as-rolled alloy at corresponding

\footnotetext{
${ }^{a}$ Corresponding author: yang760507@163.com. This research was supported by university's scientific research project of JingChu University of Technology(No. 2013BK02)
} 
temperatures. Fig. 1 indicates that the ultimate tensile strengths of the as-rolled and heat-treated alloys decrease very slowly with increasing temperatures up to $200^{\circ} \mathrm{C}$ which is desirable for high temperature applications obviously. However, the ultimate tensile strengths of both as-rolled and heat-treated alloys dropped apparently at $235^{\circ} \mathrm{C}$ possibly due to new slip system of magnesium alloys activating at nearly $220^{\circ} \mathrm{C}$.

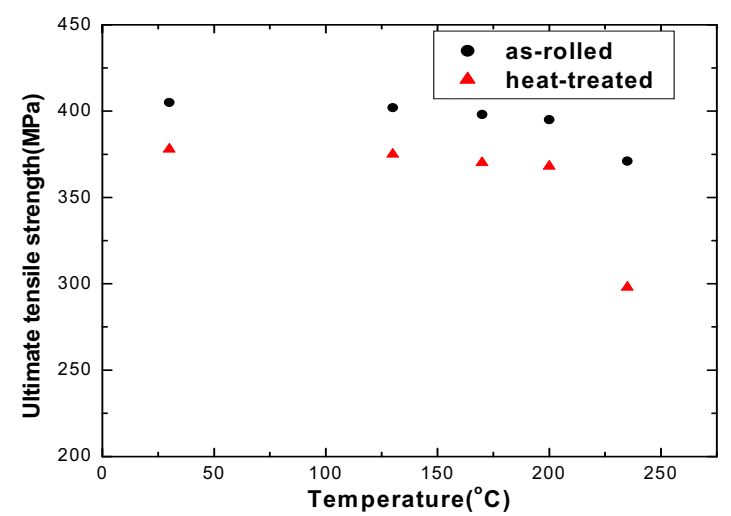

Figure 1. Temperature dependence of ultimate tensile strengths for the as-rolled and heat-treated Mg-12Gd-3Y-0.5Zr alloys.

\subsection{Fatigue behaviors at different temperatures}

Isothermal fatigue tests were performed at different temperatures under stress control. Figs.2a-c demonstrate the isothermal S-N curves of the as-rolled Mg-12Gd-3Y$0.5 \mathrm{Zr}$ at room temperature and $235^{\circ} \mathrm{C}$, and the heattreated alloy at $235^{\circ} \mathrm{C}$, respectively. All tests were carried out on an MTS810 fatigue testing machine at a constant frequency of $20 \mathrm{~Hz}$. The isothermal fatigue strength at $5 \times 10^{6}$ cycles was obtained as shown in Fig.3a. The dependences of the ratio of fatigue strength over ultimate tensile strength on temperatures for the as-rolled and heat-treated $\mathrm{Mg}-12 \mathrm{Gd}-3 \mathrm{Y}-0.5 \mathrm{Zr}$ alloys are shown in Fig. 3 b. The ratio is within a range of about 0.5 to 0.2 when the temperature varies from ambient temperature to $200^{\circ} \mathrm{C}$.

From Figs.2 and 3, we can see that although the heattreated $\mathrm{Mg}-12 \mathrm{Gd}-3 \mathrm{Y}-0.5 \mathrm{Zr}$ has slight lower ultimate tensile strength than that of as-rolled counterpart, it has higher fatigue strength. It means that in the cyclic loading condition, the heat-treated alloy would be preferential to be used at the temperatures ranged from ambient up to $200{ }^{\circ} \mathrm{C}$. However, when the temperature reaches $235^{\circ} \mathrm{C}$, both the as-rolled and heat-treated alloys would not be used due to their fatigue strengths decreasing drastically. It is believed that fatigue strength increases with increasing ultimate tensile strength and/or increasing elongation-to-failure[4,5]. Higher elongation-to-failure of heat-treated $\mathrm{Mg}-12 \mathrm{Gd}-3 \mathrm{Y}-0.5 \mathrm{Zr}$ offsets the negative effect of its lower ultimate tensile strength and finally the higher fatigue strength can be achieved at different temperatures except $235^{\circ} \mathrm{C}$.
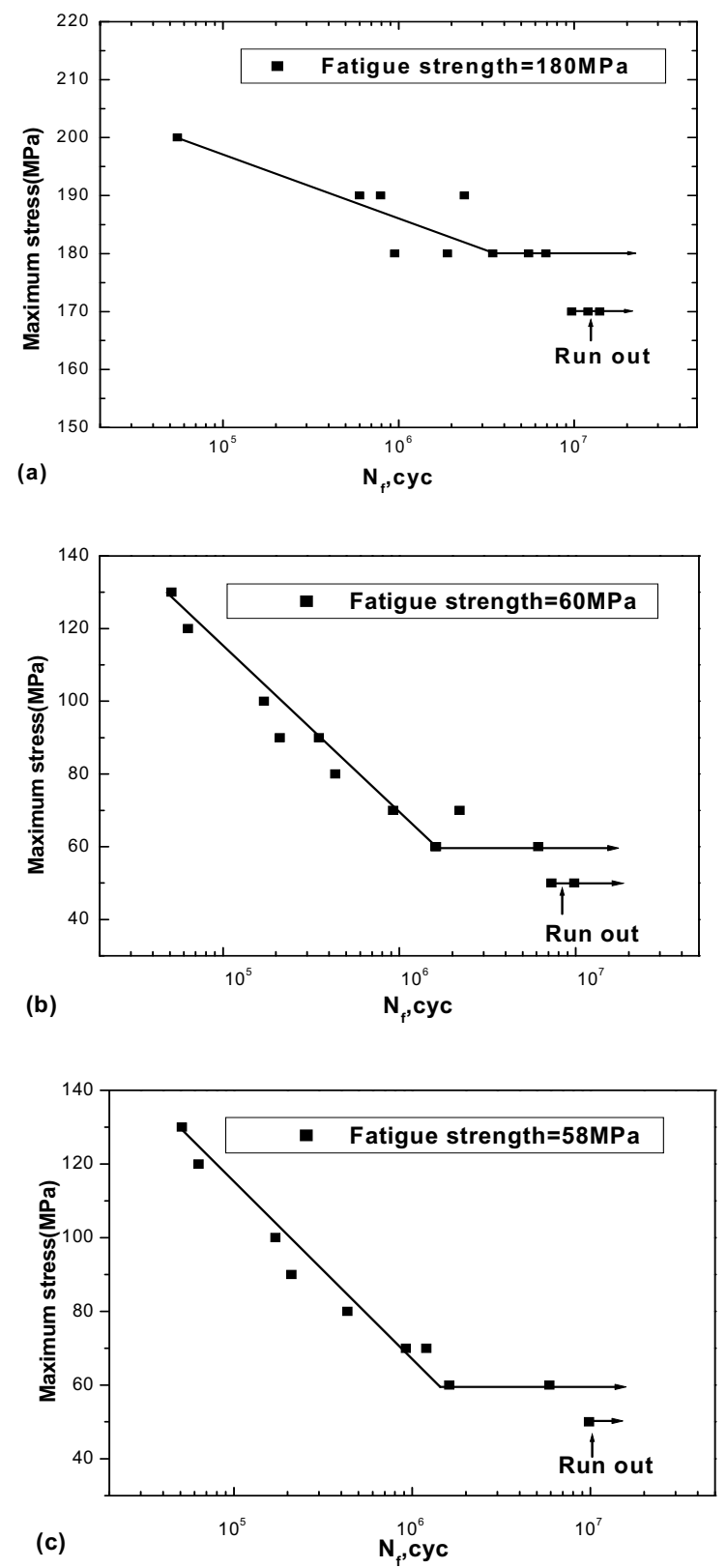

Figure 2. S-N curves of the as-rolled Mg-12Gd-3Y-0.5Zr (a) at room temperature, (b) at $235^{\circ} \mathrm{C}$, (c) S-N curve of the heattreated $\mathrm{Mg}-12 \mathrm{Gd}-3 \mathrm{Y}-0.5 \mathrm{Zr}$ at $235^{\circ} \mathrm{C}$.

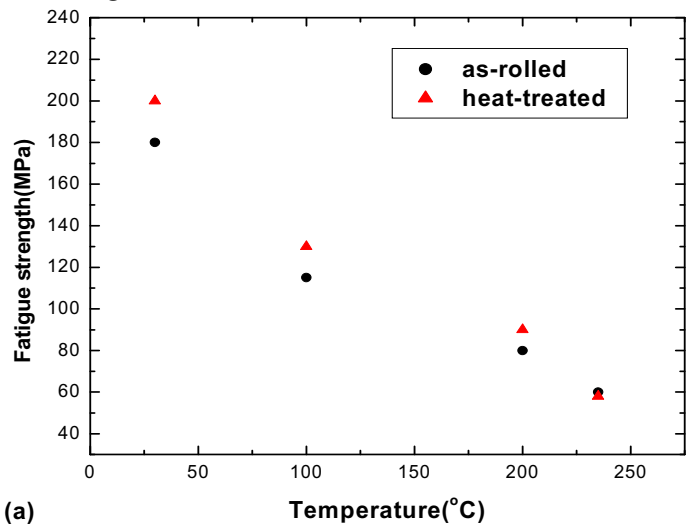




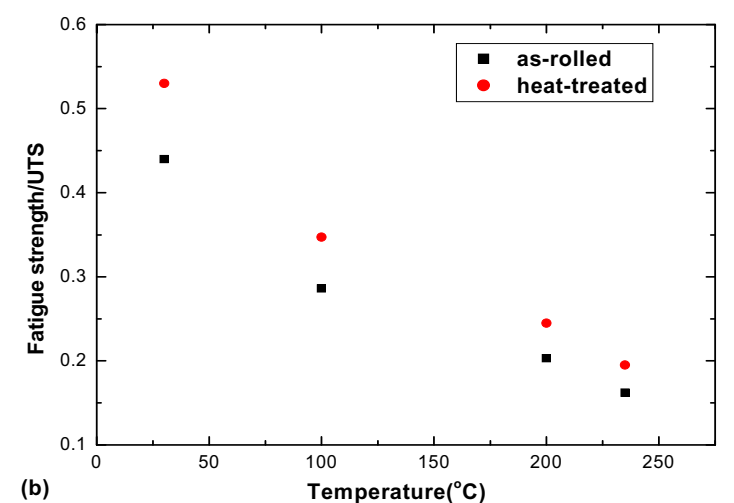

Figure 3. (a) fatigue strength vs temperature and (b) the ratio of fatigue strength over ultimate tensile strength vs temperature for the as-rolled and heat-treated Mg-12Gd-3Y-0.5Zr alloys.

\subsection{Fatigue crack origins}

Some of the fatigue crack initiation sites of the asrolled and heat-treated $\mathrm{Mg}-12 \mathrm{Gd}-3 \mathrm{Y}-0.5 \mathrm{Zr}$ alloys tested under different stresses and at different temperatures are shown in Fig. 4. In the present experiment, it is noted that all of fatigue crack origins initiated at the sample surface no mater what stresses and temperatures applied. Ridges are obviously observed on the facture surface as shown in Fig. 4c which indicates that it has characteristic of multiple fatigue origins as marked by arrows with increasing temperatures. Similar to Fig. $4 \mathrm{c}$, there are several fatigue crack origins in Fig. 4d due to high cyclic stress applied, however, the fatigue crack propagation zone is rather smooth for heat-treated alloy than that for as-rolled alloy observed in low magnification. The reason is partly due to more precipitate occurring in the heattreated alloy which restricts the crack meandering.

In the extruded magnesium alloys without RE element additions, for example AZ31, usually the yield stress asymmetry between tension and compression caused by texture and twining exists. We found that twining and detwining [6] play key roles for crack initiation in the low cycle fatigue for AZ31. At the same time, the work in our group revealed that twining-involved fatigue damage process could also play a important role in the very high cycle fatigue regime for AZ31. However for $\mathrm{Mg}-12 \mathrm{Gd}-$ $3 \mathrm{Y}-0.5 \mathrm{Zr}$ alloy the reasons for fatigue crack not be observed to initiate from twinning-detwining process may be as follows. In the present extruded alloys the texture is weak and no obvious yield asymmetry exists, in other words, twining and detwining during deformation are rare. Under isothermal fatigue test above $100^{\circ} \mathrm{C}$, cyclic slip was the main form of plastic deformation and the cyclic twining and detwining would not take place substantially. During cyclic deformation the persistent slip leads to surface roughening which makes it possible for the crack to initiate at surface, particularly, at the position where the slip band impinges with the oxide inclusion or large second phase. At the same time environmental effect plays an important role in crack initiation for these two alloys tested at high temperatures. Oxides formed at the surface make the surface roughening and embrittlement, and the crack is prone to initiate around the oxides. It can be observed from Fig. 4b that there are some oxides near the crack initiation sites. As a result, cyclic slip combined with environmental effect may be the main crack initiation mechanism. RE element additions result in dispersion of second phases and fine grains which restrains the fatigue crack growth and hence improves fatigue strengths of the as-rolled and heat-treated $\mathrm{Mg}-12 \mathrm{Gd}-3 \mathrm{Y}-0.5 \mathrm{Zr}$ alloys.
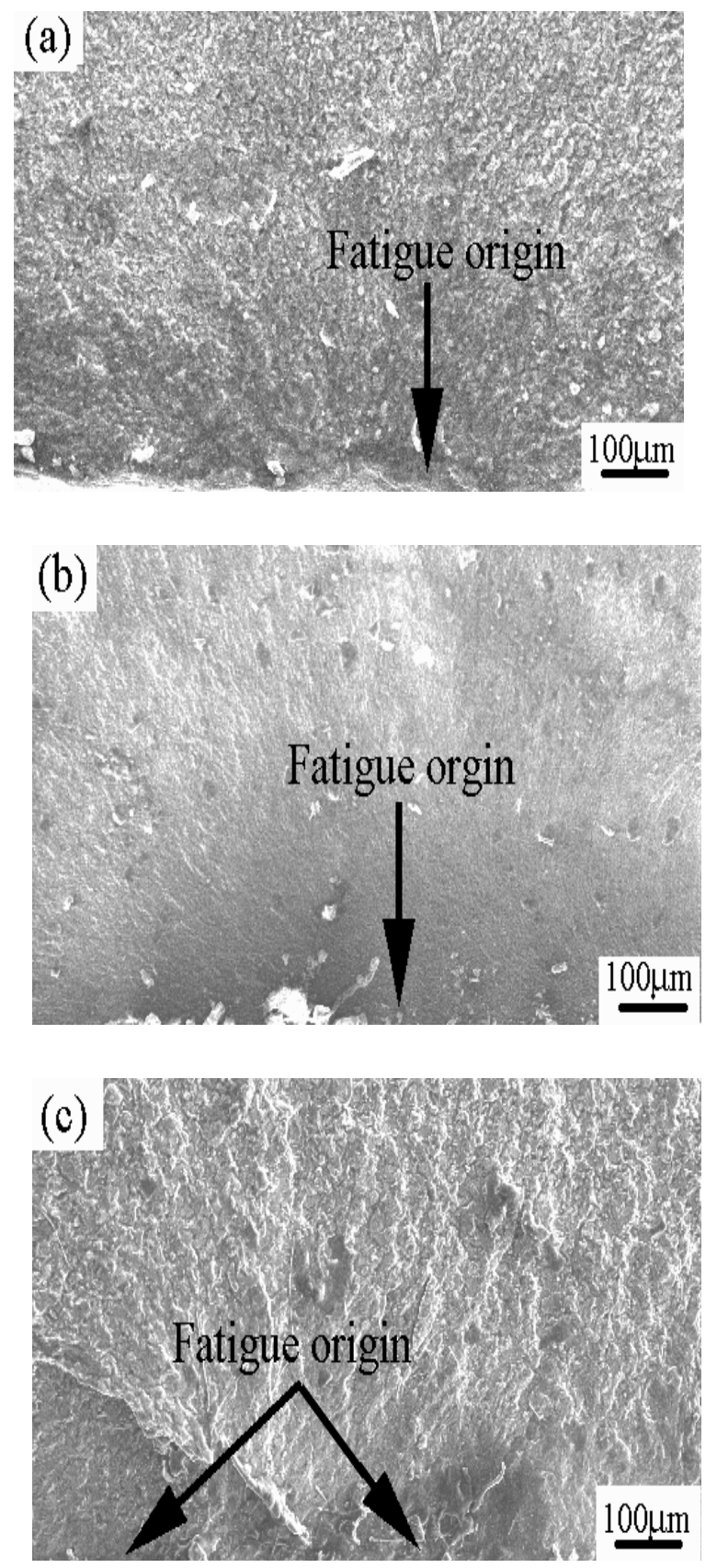


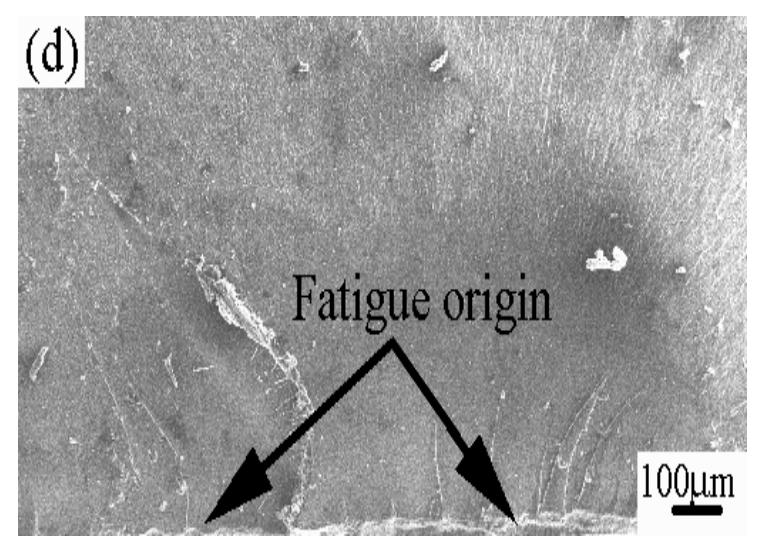

Figure 4. SEM photographs of fatigue origin: as-rolled $\mathrm{Mg}$ $12 \mathrm{Gd}-3 \mathrm{Y}-0.5 \mathrm{Zr}$ tested at $(\mathrm{a}) 100^{\circ} \mathrm{C}, \sigma_{\mathrm{a}}=110 \mathrm{MPa}$, $\mathrm{N}_{\mathrm{f}}=1.17 \times 10^{7} \mathrm{cyc}$; (b) $200^{\circ} \mathrm{C}, \sigma_{\mathrm{a}}=80 \mathrm{MPa}, \mathrm{N}_{\mathrm{f}}=2.42 \times 10^{6} \mathrm{cyc}$; (c) $235^{\circ} \mathrm{C}, \sigma_{\mathrm{a}}=50 \mathrm{MPa}, \mathrm{N}_{\mathrm{f}}=9.82 \times 10^{6} \mathrm{cyc}$; heat-treated Mg-12Gd-3Y$0.5 \mathrm{Zr}$ tested at $(\mathrm{d}) 100^{\circ} \mathrm{C}, \sigma_{\mathrm{a}}=130 \mathrm{MPa}, \mathrm{N}_{\mathrm{f}}=1.2 \times 10^{6} \mathrm{cyc}$.

\section{Conclusions}

(1) The as-rolled and heat-treated Mg-12Gd-3Y-0.5Zr alloys have a good combination of ultimate tensile strength and ductility at temperatures from ambient up to $200^{\circ} \mathrm{C}$.

(2) The ultimate tensile strength of the heat-treated Mg-12Gd-3Y-0.5Zr alloy is slightly lower than that of the as-rolled counterpart, however, the fatigue strength of the heat-treated $\mathrm{Mg}-12 \mathrm{Gd}-3 \mathrm{Y}-0.5 \mathrm{Zr}$ alloy is higher than that of the as-rolled alloy.

(3) Fatigue crack initiates at the surface and has the characteristic of multiple fatigue origins with increasing temperatures and/or high cyclic stresses. Precipitates in the two alloys play essential roles in the tensile and fatigue tests.

\section{Acknowledgement}

This work was funded by scientific research project of Jingchu University of Technology (NO. 2013BK02). We would like to thank Yang Fan for kind assistance on SEM and TEM analysis.

\section{References}

1. W. J. Kim, S. W. Chung, C. S. Chung, D. Kum. Acta Mater. 49, 3337(2001)

2. M.H. Idris: AFS Trans. 104, 237 (1996)

3. R.E. Brown: Light Metal Age. 55 (7-8), 72(1997)

4. Y. Yang and Y. B. Liu, Mater. Characterization. 59, 567(2008)

5. X. M. Yang, H.J Yang, F. Yang, S.M. Yin, W. Wang, S.X. Li, Q.D. Wang. J. Mater. Sci. Technol. 25(6),731(2009)

6. S.M. Yin, F. Yang, X.M. Yang, S.D. Wu, S.X. Li and G.Y. Li: Mater. Sci. Eng. A. 494, 397(2008) 